\title{
Development of a water code of practice for internal plumbing in Kuwait
}

\author{
M. Al-Senafy, E. Azrag, M. Al-Otaibi \& A. Al-Khalid \\ Hydrology Department, Water Resources Division, \\ Kuwait Institute for Scientific Research, Kuwait
}

\begin{abstract}
The objective of this paper is to develop a Kuwaiti water code of practice for internal plumbing of potable water supply in homes, apartment complexes, and public facilities. In order to prepare the code, data collection was accomplished in three categories, namely, communication with governmental authorities; communication with local industries and plumbing service companies; and collecting, and studying international codes applied in other countries. The final outcome of this project was a "Uniform Potable Water - Plumbing Code of Kuwait (UPPCK)". The UPPCK is composed of seven chapters and three appendices. It includes the standards for plumbing material specifications and general regulations, the requirements for plumbing fixtures and fixture fittings, water supply roof appliances and the ground and elevated storage tanks, approved methods for the design of water supply and distribution, and finally the protection of the water supply network from back water flow. The implementation of the UPPCK will have a positive influence on water conservation by reducing wastage of water and will ensure better health of consumers.
\end{abstract}

Keywords: management, regulations, fixtures, fittings.

\section{Introduction}

On the basis of the plans and strategies of the Ministry of Electricity and water in Kuwait (MEW) to maintain the quality and the consumption of the drinking water, Kuwait Institute for Scientific Research (KISR) has completed several research project requested and funded by MEW. This paper summarizes the 
outcomes of one of these completed projects titled "Development of Water Code of Practice for Internal Plumbing in Kuwait”.

This paper presents the developed water code of practice which is titled the "Uniform Potable Water Plumbing Code of Kuwait" (UPPCK), the steps leading to its development, the suggested activities to achieve its propagation and proper application.

The UPPCK explains and details the standard acceptable code of practice and the principles for water supply and plumbing inside homes, apartment complexes, and public facilities, it is the basis of nationally consistent regulations for all on-site potable water plumbing installations and plumbing network design certification and authorization. The objectives of the UPPCK includes providing an appropriate level of protection for the community, amenity, public health, water utility operator's infrastructure, water resources and the environment, which at the same time encourages the conservation of water and energy resources. An example of the importance of the UPPCK is the case of availability of a standard procedure for testing the competence of newly installed water supply networks; the absence of such a procedure will culminate disputes and erroneous interpretations. The UPPCK should significantly reduce the need for increasing water production in Kuwait beyond reasonable limits. In an international study it was proven that application of national plumbing code conserve water supply by significant percentages [1]. The study found forecasted water production, due to the application of national plumbing code, reduced by 5 per cent in 2010, climbing to 8 per cent water savings by the year 2020 .

Worldwide, the first version of the UPC was developed in 1945, the UPC 2003 version was considered the first plumbing code that was developed via true consensus process, and the second edition of the UPC 2006 edition contains the most current approaches in the plumbing field. KISR has commended all said characteristics of the UPC, and the benefited from the vast experience of all the diverse environments, and to build the code on such sound foundation. Consequently KISR and the International Association of Plumbing and Mechanical Officials (IAPMO) worked jointly in developing the UPPCK.

\section{Methodology}

Several available documents on plumbing code have been reviewed. It has been concluded that the UPC 2006 of America can be adopted as the model for the Uniform Potable Water Plumbing Code of Kuwait. The relevant portions of the 2006 UPC, developed by IAPMO, was modified for application in Kuwait.

The relevant chapters and the appendices of the 2006 UPC to Kuwait environment were identified, and modifications that were required were carried out to produce the UPPCK document.

The data collection was accomplished in three categories, namely, communication with governmental authorities; communication with local industries and plumbing service companies; and collecting, and studying international codes applied in other countries. 
After visiting the importing section of the Ministry of Commerce, it was concluded that there are no rules controlling the quality of imported plumbing materials.

Since the plumbing material manufacturing sector will be the most impacted sector by the application of the UPPCK, as the specifications adopted in the code require certification of product by a third party to insure compliance with the stipulated Kuwaiti or international standards and specifications

Several local contractors were contacted during the course of this study, to learn about the typical practices followed for internal water plumbing practice in Kuwait. A number of plumbing installing and plumbing importing companies were interviewed at their offices and at some of their job sites. Some of the important observations made during the interviews were the following:

- Contractors are not aware of any official guide made by the MEW to standardize and regulate potable water plumbing in buildings. However, they signified their willingness to follow and contribute to any such code of practice.

- Some acceptable practices were already established within the plumbing service industry in Kuwait.

\section{Results}

It should be noted that one of the main purposes of the code was to include the conservation of water, which sets the UPPCK apart from many international plumbing codes, including the UPC which was used as the template for the Kuwaiti code. Consequently, relevant changes in the appropriate sections and code's articles in all chapters were made to reflect this emphasis. As well, articles were added mainly for the benefit of the water conservation objective.

The UPPCK is composed of seven chapters and three appendices successively, with each chapter briefly presented with issues requiring attention for further discussion highlighted in the subtitle of respective chapter.

\subsection{Chapter 1: Definitions}

The chapter includes the definition of various terms as intended and used in the UPPCK. The definitions of the terms shall be viewed as an integral part of the code, and all statements and articles in the code are interpreted using these given definitions.

\subsection{Chapter 2: Administration}

This section provides the purpose of the code, i.e., "an ordinance providing minimum requirements and standards for the protection of the public health, safety, conservation of water resource and welfare". Its scope is the "erection, installation, alteration, repair, relocation, replacement, addition to, use, or maintenance of potable water plumbing systems", and the way the code is organized and should be enforced. To accomplish the purpose of the code, it is 
required that plan specifications, drawings, and other information deem necessary should be submitted for approval, prior to the commencement of any work listed in the scope. The articles deal with the application of the UPPCK to existing plumbing system.

The most important issue in this chapter defines the Legal Authority which is duly appointed by the MEW, although as of yet, this authority or office has not been established by the MEW. The code refers to it as the Legal Authority, and the term can be replaced globally in the document, once it is named and established. It further details their authority and right of entry, their ability of ordering stoppage and disconnecting utilities from work site in violation of the code and limit their liability while performing these duties.

This chapter establishes that violation of any of the articles of the code is considered a misdemeanor punishable by law. Issuance of permits and the following inspections are stipulated in several articles of this chapter. This section also deals with the application, procedures and requirements; it also details the plan specifications and permit validity and expiration. The UPPCK strictly sanctions that the work carried out should be undertaken by a licensed plumber or a plumbing service company. The licenses will be issued by the Legal Authority to qualified entities.

Fees for application and inspection are discussed in the articles of this chapter. Example fee schedule for obtaining permits from the "Legal Authority" by the consumers [2] is included in this chapter.

\subsection{Chapter 3: Material Specifications and General Regulations}

The chapter is concerned with the regulations to be followed in the implementation of a plumbing system. The specific areas covered under this chapter are as follows:

- Materials - Standards and Alternates.

- The prohibited location section limits application of the permit to the facilities cited on the permit only.

- Workmanship. This section highlights the important criteria for design and installation practices.

- The prohibited fittings and practices are dealt with in the following section. Practices such as tapping pipes for making connections and concealing defects are prohibited.

- Protection of Piping, Materials, and Structures.

- Hangers and Supports.

- Trenching, Excavation, and Backfill.

- Joints and Connections section gives specification for the majority of pipe jointing fittings that include threaded joints, soldered, flared, mechanical, pressure-lock, pressed fitting, cement solvent, heat fusion, brazing and welding joints.

- Test Gauges are also specified in the last articles of this chapter. 


\subsection{Chapter 4: Plumbing Fixtures and Fixture Fittings}

The specifications for the plumbing fixtures and fittings to be used are also presented. These have been presented in sequence starting with general requirements and material specifications; fixtures and prohibited fixtures, minimum acceptable number of fixtures. Also general instructions for installations are covered in the installation articles under each individual fixture. General requirements and measures for water conservation are included under the first articles of general requirements.

Although strainers and connections, water closets, urinals, floor drains and shower stalls, bathtubs and whirlpool bathtubs and bidets are not strictly potable water fixtures, they are duly included in this chapter of the code for completeness.

\subsection{Chapter 5: Water Heaters and Plumbing Appliances on Roof}

The chapter contains two major parts, indicates; the water heaters and other plumbing appliances on the roof. In Kuwait, almost all water heaters (residential, governmental, and commercial buildings) are of the electrical type, and almost always, installed in the appliances room on the building roofs, except in apartment buildings where they are installed above false ceiling or attics. Specifications related to water heaters and their installation and connection are presented in this chapter.

\subsection{Chapter 6: Water Supply and Distribution}

Chapter 6 is considered the principal section of the UPPCK, as it specifies the requirements for the water supply system within buildings.

\subsection{Chapter 7: Cross-Connection Control}

From a health point of view, almost all the secondary pollution of drinking water supplies stems from back siphonage of polluted water into the internal network especially in multistory buildings and houses. This chapter specifies cross connection control and the provisions thereof.

\subsection{Appendix A: Mandatory Referenced Standards}

This appendix consists solely of a table that lists all the standard numbers, respective standard title and the area of application of the concerned standard for materials, equipment, joints and connections referred to in the text.

\subsection{Appendix B: Recommended Rules for Sizing the Water Supply System}

The appendix presents an outline of an alternative procedure to be followed in sizing the water supply system in a building, and provides the relevant tables and charts for carrying out the necessary computations and estimations. 


\subsection{Appendix C: Alternate Plumbing Systems}

The appendix provides clarification of procedures for the design and approval of engineered plumbing systems, alternate materials, and equipment not specifically covered in other parts of the code.

\section{Application of the UPPCK}

Following acceptance of the UPPCK draft by the MEW, some tasks will still be accomplished toward propagating and applying the water code in the State of Kuwait. These tasks are as follows:

- Translating the UPPCK in Arabic and undertaking a technical review of the translated version.

- Holding of a national workshop among concerned parties.

- Agreement with the MEW on modifications resulting from the workshop and other issues.

- If needed, editing of the two versions of the code.

- Approving the legal language of the code by legal specialists.

- Passing the code through the legalization channels (e.g., Ministerial Counsel) to be enacted as a law in the State of Kuwait.

- Production of the UPPCK book in Arabic and English versions.

- Distribution of the final book of the UPPCK to the public.

- Press releases, training workshops, and public lectures to propagate the code.

\section{Conclusions}

A code of practice for the internal plumbing of freshwater distribution within residential, commercial, industrial, government and public buildings in Kuwait, titled Uniform Potable-Water Plumbing Code of Kuwait (UPPCK) has been developed with emphasis on water conservation. UPPCK covers the plumbing system related to the distribution of potable water only. All governmental, autonomous and semi-autonomous authorities and private companies in Kuwait having a stake in water distribution, consumption and management were consulted in developing the code. These included the Ministry of Electricity and Water (MEW), Environmental Public Authority (EPA), Public Authority for Housing Welfare (PAHW), Public Authority for Industry (PAI), Kuwait Chamber of Commerce and Industry (KCCI), major local manufacturers of plumbing fixtures, a number of importers of plumbing fixtures and companies specializing in the installation of plumbing systems.

The development and adoption of UPPCK will have positive influence on water conservation by reducing wastage of water and will ensure better health of the consumers through prevention of contamination from backflows of polluted water and dissolution of unwanted trace materials from substandard fixtures. It will regulate the local industry producing plumbing fixtures, businesses 
importing such fixtures and companies installing plumbing in different types of premises so that only approved and standard materials, fixtures and methods are used in the plumbing systems in the country. UPPCK will thus benefit both the authorities in charge of the distribution and management of the water resources of the country and the consumers.

The planned workshop on UPPCK will present the developed code to all entities in the country that either has a stake in the fresh water supply or are concerned with the security of water supply and its quality. The provisions of UPPCK will be disseminated among the general public through local media and public presentations. The feedbacks from the participants and public will help in updating the code in a manner that will make it acceptable to all concerned and facilitate its acceptance by the legislative body for making it a legal document. The training program for the people who will implement the code and those who will supervise this implementation will strive to ensure that the aim for which UPPCK has been developed is achieved within the shortest period of time.

\section{Acknowledgements}

The Hydrology Department of the Water Resources Division at the Kuwait Institute for Scientific Research (KISR) would like to express its appreciation to the Ministry of Electricity and Water (MEW) for their sponsoring and supporting of this study. Deep gratitude is extended to the International Association of Plumbing and Mechanical Officials (IAPMO) for participating in drafting the initial manuscript of the UPPCK and authorizing KISR to use their relevant material.

\section{References}

[1] Dickinson, M. A.; L. A. Maddaus and W. O. Maddaus. 2003. Benefits of the United States nationwide plumbing efficiency standards. Water Science \& Technology: Water Supply 3(3):231-237.

[2] MEW, KISR, and IAPMO. 2007. Uniform Potable Water Plumbing Code of Kuwait (UPPCK). Kuwait Institute for Scientific Research. 